\title{
Removal of hardness from drinking water by electrocoagulation using iron electrodes
}

\author{
P. D. Nemade ${ }^{1 *}$, K. T. Patil ${ }^{2}$, S. J. Kadbhane ${ }^{2}$, M. B. Patil ${ }^{2}$, Y. H. Tambe ${ }^{3}$ \\ ${ }^{1 *}$ Professor, Department of Civil Engineering, MVPS's KBT College of Engineering, Nashik, Savitribai Phule \\ Pune University, Pune, Maharashtra, India. \\ (Corresponding author: Email: pravin.nemade@gmail.com) \\ ${ }^{2}$ Faculty of Civil Engineering, MVPS's, KBT College of Engineering, Nashik, Maharashtra, India \\ ${ }^{3}$ Research Scholar, Department of Civil Engineering, Dr. D.Y. Patil Institute of Technology, Pimpri, Pune, \\ Savitribai Phule Pune University, Pune, Maharashtra, India. \\ Email: yhtcivil.svpm@gmail.com
}

Received Date : October 06, 2021 Accepted Date : October 27, 2021 Published Date : November 07, 2021

\begin{abstract}
In the present study laboratory studies are carried out to examine the removal of hardness by electrocoagulation process from drinking water using iron rod electrodes in batch mode. The purpose of this study was to investigate the efficiency of EC process in removal of water hardness through iron-rod electrodes in varying conditions. Experimental water sample was taken from water distribution network of local area Pune City, Maharashtra state, India. The indices for calcium and total hardness removal in $\mathrm{pH}(4.0,7.0$, and 10.0), electrical potential of 12 and $24 \mathrm{~V}$ and reaction times of 5 minutes to 30 minutes were measured. The maximum efficiency of hardness removal which was obtained at $\mathrm{pH}$ 10.0 , voltage of 12 and reaction time of $60 \mathrm{~min}$ are equal to $98.5 \%$ and $97.5 \%$ for calcium and total hardness, respectively. Final pH of remained solution has also increased which rises with acidic $\mathrm{pH}$ and decreases in alcoholic $\mathrm{pH}$, so the results demonstrate the direct effect of $\mathrm{pH}$, potential difference and reaction time on hardness removal using EC process.
\end{abstract}

Key words: Electrocoagulation, Hardness removal, Iron electrodes, Reaction time

\section{INTRODUCTION}

Water is elixir of life and available for human consumption limited and likewise, available drinking water has been reduced because of the pollution created naturally and due to anthropogenic activities. Amongst water quality parameters, hardness is generated due to carbonates of calcium, magnesium and in lower traces; aluminum, iron and other bivalent and trivalent. Furthermore, water hardness is a vital parameter in industrial water consumption in manufacturing of high-quality products [1]. Hard water causes many problems in domestic and industrial consumptions like scale formation in hot water pipes, kitchen devices, water supply facilities, boilers, cooling towers, membrane clogging, declining efficiency of heat exchangers and reaction to the soap and formation of hard foam [2]. Moreover, soft water is preferred to be hard enough to prevent Nephritis. Hence, water hardness is one of the compounds which has to be removed and its process is called water softening [2]. WHO Recommendation for drinking water's hardness is based on maximum $500 \mathrm{mg} / \mathrm{l}$ calcium carbonate [3]. Numerous technologies which need adding chemicals for water softening, are chemical precipitation and ion exchange and those which do not need to add chemicals; include reverse osmosis, electro-dialysis, nano-filtration, crystallization, distillation and evaporation $[4,5]$. These techniques have some problems such as increased sludge, permanent water hardness, water salts like sodium, annual high operation costs, sediment formation on membrane, which require an effluent post treatment and disposal of residual sludge [2, 6]. Recently, growing demand for high quality water has justified the development of modern and low cost technologies for hard and very hard water softening [6]. One of these techniques is electrochemical technology such as electrocoagulation process (EC), which is being used for the removal of ions, organic matters, colloidal and suspended particles, dyes, surfactants, oil and heavy metals from aqueous environments [7-11]. This procedure has a broader potential to improve the faults of other water softening equipments. Electrocoagulation process involves three stages; coagulant formation through dissolution of metal ions of anode reactor electrode, destabilization of pollutants, suspended particles and de-emulsification, and aggregation of instable phases and floc-forming [12]. Destabilization of pollutants, suspended particles and de-emulsification mechanism can be established through dispersed double layer compression, ion neutralization species existing in water and wastewaters, and flocs and sludge forming [9]. In this study, iron electrodes have been used in electrocoagulation (EC) process. Following equations, illustrate $\mathrm{EC}$ process in relation to iron electrode [10]: 
P. D. Nemade et al., International Journal of Emerging Trends in Engineering Research, 9(11), November 2021, 1413 - 1417

\section{1) Anode}

$\mathrm{Fe}_{(\mathrm{s})} \rightarrow \mathrm{Fe}^{2+}{ }_{(\mathrm{aq})}+2 \mathrm{e}^{-}$

$\mathrm{Fe}^{2+}{ }_{(\mathrm{aq})}+2 \mathrm{OH}_{(\mathrm{aq})}^{-} \rightarrow \mathrm{Fe}(\mathrm{OH})_{2(\mathrm{~s})}$

2) Cathode

$2 \mathrm{H}_{2} \mathrm{O}_{(\mathrm{l})}+2 \mathrm{e}^{-} \rightarrow \mathrm{H}_{2(\mathrm{~g})}+2 \mathrm{OH}_{(\mathrm{aq})}^{-}$

3) Overall

$\mathrm{Fe}_{(\mathrm{s})}+2 \mathrm{H}_{2} \mathrm{O}(\mathrm{l}) \rightarrow \mathrm{Fe}(\mathrm{OH})_{2(\mathrm{~s})}+\mathrm{H}_{2(\mathrm{~g})}$

From iron electrodes, Ferro ions are released into the solution through electrolytic oxidation of anode electrode and produce metal hydroxides after reacting with hydroxide monomer and polymer ions which completely depend on $\mathrm{pH}$ of the solution $[10,12]$. Flocs generated through EC process are much larger than chemical flocs and contain more stable acid duric and less water bonds [24]. Gases produced through anode and cathode electrodes during electrolysis cause flotation and mixing gives better pollutants removal [12]. Contamination of the water caused by the application of heavy metals in the atmosphere has created alarm around the world [23]. EC process, compared with other techniques, enjoys some advantages like robust design, less resistance time, no chemicals, low sludge production, sludge stability, suitable sedimentation of sludge, dewatering and environmental compatibility $[7,9,13]$. The objective of the present study was to investigate EC process efficiency to remove hardness from water using rod-iron electrodes as a substitute for other water softening methods and determining optimal current density and $\mathrm{pH}$.

\section{MATERIALS AND METHODS}

A laboratory experiments were performed in a batch EC reactor. Water samples were taken from local water distribution system near Pune, Maharashtra, India. Characteristics of water are shown in Table no. 1. Electrocoagulation reactor setup shown in Fig. 1 which include power supply (alternating current transformer to direct current) and iron-rod electrodes with a diameter of 2 $\mathrm{mm}$ connected at a distance of $2 \mathrm{~cm}$ into a glass beaker having volume of $1.5 \mathrm{~L}$ [7]. Electrodes were connected to the power supply in a monopolar and parallel arrangement which consume less energy than the series arrangement. For precise observations, each electrode was connected to positive and negative poles directly and alternately [14]; and magnetic stirrer used for mixing with needle for a speed $375 \mathrm{rpm}$. Water sample hardness rate was measured using EDTA Titrimetric method based on techniques mentioned in the standard methods of water and wastewater experiment [3]. $\mathrm{pH}$ of the sample was adjusted using sulphuric acid and normal sodium hydroxide; having water samples of different $\mathrm{pHs}(4$, 7 , and 10) under three voltages (12 and 24) and three reaction periods were tested: $5,10,30$, and $60 \mathrm{~min}$. Samples were chosen $(25 \mathrm{~mL})$ from the middle of the reactor using pipettes. Then, all samples were passed through a membrane filter with a size of $0.45 \mu \mathrm{m}$ in order to remove the formed flocs. Lastly, filtered samples were analyzed concerning their calcium and total hardness.
Table 1: Characteristics of drinking water

\begin{tabular}{|c|c|c|}
\hline $\begin{array}{l}\text { Sr. } \\
\text { No. }\end{array}$ & Parameters & Values (mg/litre) \\
\hline 1 & $\begin{array}{l}\text { Total hardness }(\mathrm{mg} / \mathrm{L} \\
\left.\mathrm{CaCO}_{3}\right)\end{array}$ & 315 \\
\hline 2 & $\begin{array}{l}\text { Calcium hardness (mg/L } \\
\left.\mathrm{CaCO}_{3}\right)\end{array}$ & 140 \\
\hline 3 & $\begin{array}{l}\text { Phenolphthalein alkalinity } \\
\left(\mathrm{mg} / \mathrm{L} \mathrm{CaCO}_{3}\right)\end{array}$ & 45 \\
\hline 4 & $\begin{array}{l}\text { Methyl orange alkalinity } \\
\left(\mathrm{mg} / \mathrm{L} \mathrm{CaCO}_{3}\right)\end{array}$ & 305 \\
\hline 5 & Turbidity & 2 to $4 \mathrm{ppm}$ \\
\hline 6 & Temperature & 28 to $30{ }^{\circ} \mathrm{C}$ \\
\hline 7 & $\mathrm{pH}$ & 7.13 to 7.55 \\
\hline 8 & $\begin{array}{lll}\begin{array}{l}\text { Total } \\
(\mathrm{mg} / \mathrm{l})\end{array} & \text { Dissolved } & \text { Solids } \\
\end{array}$ & 800 to 1100 \\
\hline 9 & $\mathrm{EC}(\mu \mathrm{s} / \mathrm{cm})$ & 160 to 410 \\
\hline
\end{tabular}

\section{RESULTS}

In this study, the efficiency of EC process using rod-iron electrodes for removing water hardness was studied as a substitute for other hardness removing techniques while using different voltages, $\mathrm{pH}$ and reaction times. The results of present study have been shown in Figs. 2-4. Concentration of hardness of water sample used in all experiments was constant. Fig.s 2-4 shows the efficiency of removing water hardness in electrical potentials of 12 and $24 \mathrm{~V}$ and $\mathrm{pH}$ of 4.0 . As it was shown, maximum removal efficiency accomplished in voltage of 24 and reaction time of 60 min with $94.6 \%$ and $97.5 \%$ for calcium and total hardness, respectively.

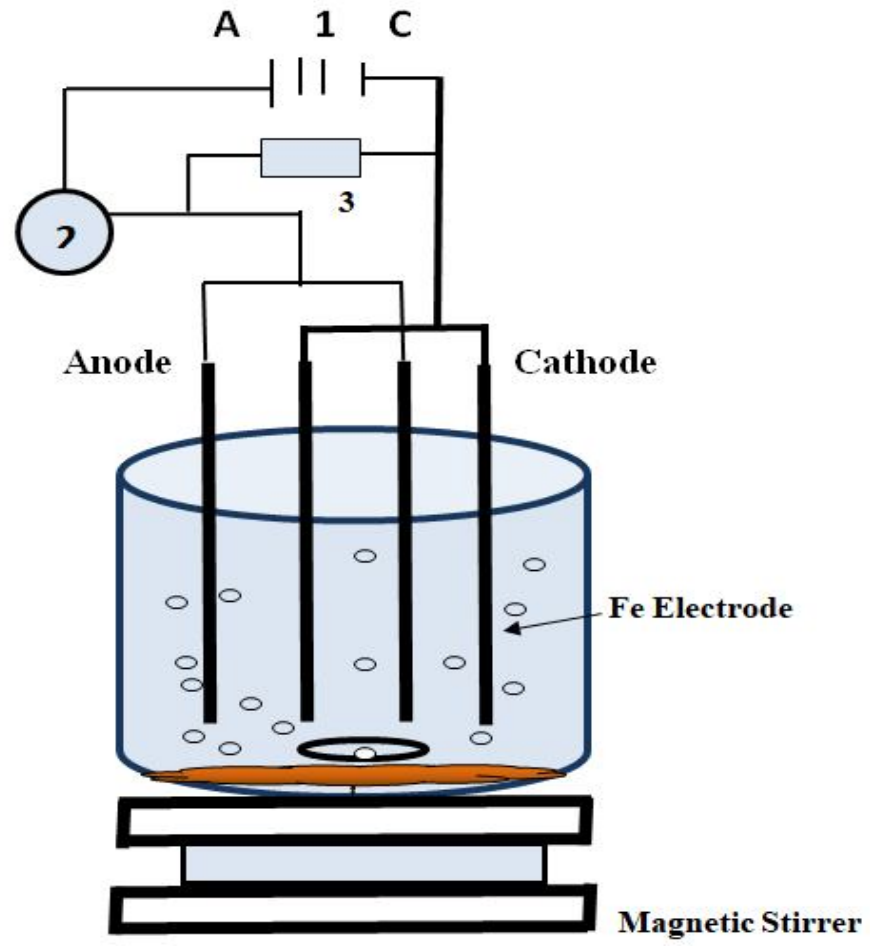

Figure 1: Electrocoagulation set up: 1: DC power supply; 2 Digital Ampere meter; 3 Volt meter 
Furthermore, final $\mathrm{pH}$ of the solution was increased from 4.0 to 10.37. Figs. 3 and 4 show the removal efficiency in the mentioned electrical potentials and in $\mathrm{pH} 7.0$ and 10 , respectively. In $\mathrm{pH} 7.0$, the maximum removal efficiency was achieved in voltage 6 and reaction time of $60 \mathrm{~min}$, which was equal to $95.5 \%$ and $95.7 \%$ for calcium and total hardness, respectively. In $\mathrm{pH} 10$, the maximum removal efficiency was $97.5 \%$ and $98.5 \%$ for calcium and total hardness, respectively and reached the potential difference of $12 \mathrm{~V}$ and reaction time of $60 \mathrm{~min}$, which considered as the maximum removal efficiency in this study. Final $\mathrm{pH}$ for remained solution has increased from 7 and 10 to 10.50 and 10.60 respectively, as $\mathrm{pH}$ does during the electrocoagulation process.

\section{DISCUSSION}

\subsection{Effect of current density}

Current density is one of the major essential factor to regulate reaction speed in EC processes as the in-situ generation of coagulants into the aqueous medium. With varying densities, the alum released into the aqueous environment decreased while the produced flocs increased, respectively; likewise, the rate of removal has also been low and high respectively [8, 9]. By increasing the density, speed and efficiency of removal process, energy and electrode consumption, the amount of produced sludge and operating costs was augmented, while, reaction time was decreased [15-17]. Thus, the effect of electrical current intensity on hardness removal from a given water was obtained in this study and observed, the removal efficiency was increased; and the current density and the time considered to be optimal for similar efficiencies were also improved, leading to decreased electrical potential differences. These results are in good agreements with the findings of arsenic removal study conducted in India, and of chromium carried out in Iran, mercury removal from water using $\mathrm{EC}$ with $\mathrm{Al}$ and $\mathrm{Fe}$ electrodes in France and removing humic acid from groundwater waters using EC in China [8, 18]. In this study, voltage 12 in reaction time of $60 \mathrm{~min}$ indicated maximum removal efficiency, i.e. $98.5 \%$ for total hardness and $97.5 \%$ for calcium hardness. Minimum removal efficiency was obtained in potential difference of $6 \mathrm{~V}$; in general, voltage 12 is suggested to achieve the desired efficiency.

\section{2. $\mathrm{pH}$ variation and its effect}

Many research reported in earlier studies, that $\mathrm{pH}$ is a significant role in EC process and highly dependent on the $\mathrm{pH}$ of solution and highly impact on forming metal hydroxide and removal mechanism of ions and pollutants $[8,12,16,18]$. Generally, $\mathrm{pH}$ changes during EC process depend on the type of used electrode and the primary $\mathrm{pH}[8,12]$. The value of $\mathrm{pH}$ increase in EC process is attributed to the formation of $\mathrm{H}_{2}$ in cathode and aggregation of hydroxide $\left(\mathrm{OH}^{-}\right)$ions in the solution [16-18]. As a result, EC process could act as a $\mathrm{pH}$ regulator $[16,18]$. In current study, three $\mathrm{pH}-$ ranges of 4,7 , and 10 were examined in order to explore the effect of $\mathrm{pH}$ on hardness removal.
Reactions for these three ranges are as follows [20]:

1) Reaction 1 (acid pH)

$2 \mathrm{Fe}_{(\mathrm{s})}+6 \mathrm{H}_{2} \mathrm{O}_{(\mathrm{l})} \rightarrow \mathrm{O}_{2(\mathrm{~g})}+4 \mathrm{H}_{2(\mathrm{~g})}+2 \mathrm{Fe}(\mathrm{OH})_{2(\mathrm{~s})}$

2) Reaction 2 (neutral $\mathbf{p H}$ )

$3 \mathrm{Fe}_{(\mathrm{s})}+8 \mathrm{H}_{2} \mathrm{O}(\mathrm{l}) \rightarrow \mathrm{Fe}(\mathrm{OH})_{2(\mathrm{~s})}+2 \mathrm{Fe}(\mathrm{OH})_{3(\mathrm{~s})}+4 \mathrm{H}_{2(\mathrm{~g})}$

3) Reaction 3 (alkaline pH)

$2 \mathrm{Fe}_{(\mathrm{s})}+6 \mathrm{H}_{2} \mathrm{O}_{(\mathrm{l})} \rightarrow 2 \mathrm{Fe}(\mathrm{OH})_{3(\mathrm{~s})}+3 \mathrm{H}_{2(\mathrm{~g})}$

Other reactions may be observed at high $\mathrm{pH}$ close to the cathode and aggravate the precipitation of the carbonate salt on this electrode, reaction equation are as these [22]:

$\mathrm{HCO}_{3}+\mathrm{OH}^{-} \rightarrow \mathrm{CO}_{3}{ }^{2-}+\mathrm{H}_{2} \mathrm{O}$

$\mathrm{CO}_{3}{ }^{2-}+\mathrm{Ca}_{2}{ }^{+} \rightarrow \mathrm{CaCO}_{3}+\mathrm{CO}_{3}{ }^{2-}$

$\mathrm{CO}_{3}{ }^{2-}+\mathrm{Mg}_{2}{ }^{+} \rightarrow \mathrm{MgCO}_{3}$

In these reactions, produced $\mathrm{H}_{2}$ goes upward and causes flotation and $\mathrm{Al}(\mathrm{OH})_{3}$ and $\mathrm{Al}(\mathrm{OH})_{2}$ precipitate. The results indicated that maximum and minimum removal efficiency was obtained in $\mathrm{pH}$ of 10.0 and 4.0, respectively. $\mathrm{pHs}$ (4.0, 7.0, and 10.0) of the remaining solution were increased to $7.37,10.54$, and 10.63 respectively, which were high in acidic $\mathrm{pH}$ and low in alkaline $\mathrm{pH}$. Concerning iron-rod electrodes, final $\mathrm{pH}$ was always higher than the primary $\mathrm{pH}$. The results of this study are consistent with the results of studies of potato chips wastewater [16] arsenic removal in India [18].

\subsection{Effect of time}

As per Faraday law, the time of electrolysis in EC process affects the rate of metal ion dissociation and released into the aqueous system [8]. Iron-rod electrodes require lesser resistance time to get a desirable removal efficiency and are economic regarding energy and electrode consumption, compared with aluminum ones [17]. The following Figures 2-4 represents, the effect of resistance time on hardness removal through EC system using rod-iron electrodes, shows good results by increasing the reaction time. So that, maximum removal efficiency was achieved in voltage of 12 , $\mathrm{pH} 10$ and the resistance time of $60 \mathrm{~min}$ which is in agreement with the results observed from arsenic removal in India [16-17], electrolytical removal of $\mathrm{Cr}^{+6}$ in UK, and chromium (VI) of synthetic solutions using EC process in Iran [17, 21, 22].

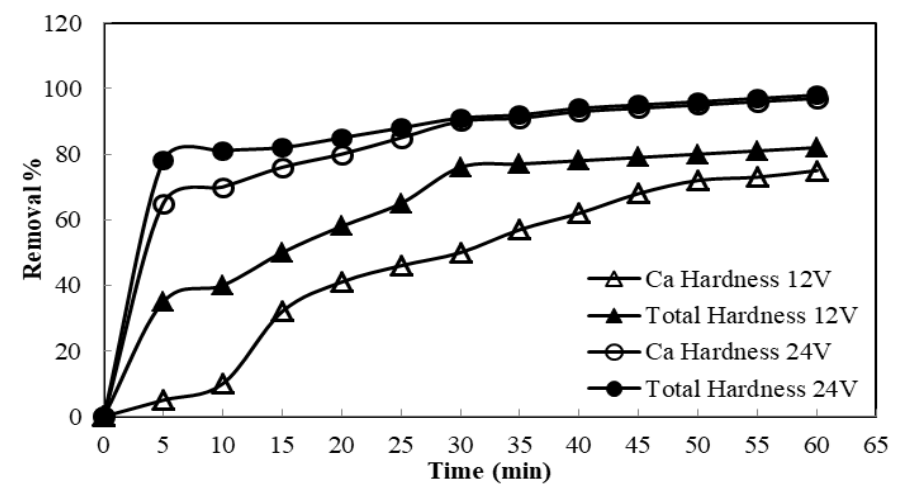

Figure 2: Removal \% vs Time with $12 \mathrm{~V}$ and $24 \mathrm{~V}$ 


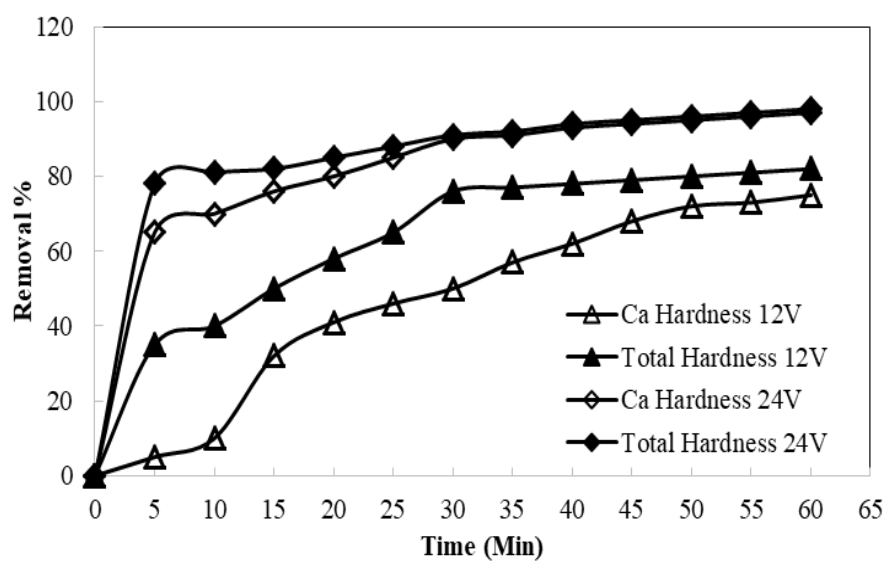

Figure 3: Removal \% vs Time with $12 \mathrm{~V}$ and $24 \mathrm{~V}$

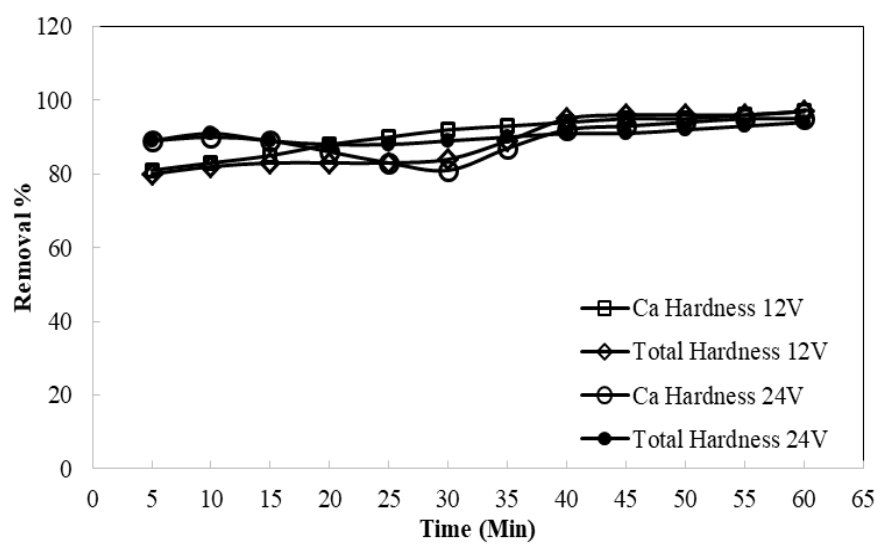

Figure 4: Removal \% vs Time with $12 \mathrm{~V}$ and $24 \mathrm{~V}$

\subsection{Electrode spacing}

As observed solutions lead resistance, increased distance between each couple of anode and cathode electrodes leads to enhance voltage. Due to diminished ions aggregation, hydroxide polymers, reduced rate of suspended solids and amalgamation of ions causing water hardness as well and electrostatic force, enhancing electrolyte constancy and spacing will eventually lead to decreased removal efficiency. In this study, spacing between anode and cathode electrodes was taken as $2 \mathrm{~cm}$, and by reducing the distance, chemical reactions were improved due to the topical increase of concentration, and consequently, removal efficiency was increased. Present result is in line with data from other researchers like COD removal from distillery spent wash using $\mathrm{EC}$ with $\mathrm{Al}$ and $\mathrm{Fe}$ electrodes [17, 21] removing humic acid from groundwater waters using EC in China and also Removal of $\mathrm{Fe}$ (II) from tap water by electrocoagulation technique in India $[18,19]$.

\subsection{Electrode material and effect}

In electrocoagulation processes, the kind of the selected electrode material has a important effect on removal efficiency. So, it is vital important to choose a suitable type of electrode. The electrode used for drinking water treatment must be non-toxic, so, iron and aluminium electrodes were selected because of their non-toxic nature, cheap and easy accessibility [16-18, 21]. In the present study, regarding the removal of arsenic, iron-rod electrodes were $65 \%$ more efficient than its aluminum equivalents [18] and due to their high efficiencies, iron electrodes were used in this study. Initially, the color of the effluent treated by iron-rod electrodes was greenish and then changed into dark-yellow due to formation ions of ferric and ferro natures. Similar results were found treating potato-chip wastewater manufacturing factory using EC process [16, 21].

\subsection{Mixing effect}

Mixing is very important to generate the metal hydroxide and creates crucial role in water treatment unit which significantly affects reactions and controlling processes like sedimentation. The rod electrodes instead of flat equivalent, it was feasible to add more electrodes in the $\mathrm{EC}$ reactor and get a better mixing process. Furthermore, time needed to accomplish the operation problems during EC process.

\section{CONCLUSION}

In this study proven that EC can be used for removing hardness from water. The maximum removal has occurred at $\mathrm{pH} \mathrm{10,} \mathrm{voltage} 12$ and in time course of $60 \mathrm{~min}$; which was $98.5 \%$ and $97.00 \%$ for total calcium hardness and finally demonstrated the importance of direct $\mathrm{pH}$, potential difference and the reaction time course on removal of hardness using EC. The overall results shows that using rod-like Fe electrodes in EC process can be effectual in removing water hardness in various situations like potential difference, acidity, reaction time and electrode type and spacing.

\section{ACKNOWLEDGEMENT}

The present research was carried out in laboratory and financially supported by the working institution and supported well for other analysis. The host institution is grateful to Savitribai Phule Pune University, Pune, Maharashtra, India.

\section{REFERENCES}

[1] A.F. Viero, et al., Removal of hardness and COD from retanning treated effluent by membrane process, Desalination 149, 145-149, 2002.

[2] J. Suk Park, et al., Removal of hardness ions from tap water using electro-membrane processes, Desalination, 202, 1-8, 2007.

[3] Standard method for examination of water and wastewater, APHA /AWWA /WEF, 20 The Ed, 2340, Washington DC. 1999.

[4] N. Kabay, et al., Removal of calcium and magnesium hardness by electrodialysis, Desalination, 149,343-349, 2002. 
[5] A. Mika, et al., Ultra-low pressure water softening: a new approach to membrane construction, Desalination, $121,149-158,1999$.

[6] J. Schaep, et al., Removal of hardness from groundwater by nanofiltration, Desalination, 119 , 295-302, 1998.

[7] C. Escobar, et al., Optimization of the electrocoagulation process for the removal of copper, lead and cadmium in natural waters and simulated wastewater, Journal of environmental management 81, 384-391, 2006.

[8] M. Emamjomeh, M. Sivakumar, Fluoride removal by a continuous flow electrocoagulation reactor, Journal of Environmental Management, 90, 1204-1212, 2009.

[9] P.K. Holt, et al., A quantitative comparison between chemical dosing and electrocoagulation, Colloids Surf. A: Physicochemical and Engineering Aspects 211, 233-248, 2002.

[10] W.L. Chou, C.T. Wang, K. Y. Huang, Effect of operating parameters on indium (III) ion removal by iron electrocoagulation and evaluation of specific energy consumption, Journal of Hazardous Materials, 2009.

[11] M. Mollah, et al., Electrocoagulation (EC)—science and applications, Journal of Hazardous Materials B 84, 29-41, 2001.

[12] C.Y. Hu, et al., Effects of co-existing anions on fluoride removal in electrocoagulation (EC) process using aluminium electrodes, Water Research 37, 4513-4523, 2003.

[13] J. Qian Jiang, et al., Laboratory study of electro-coagulation-flotation for water treatment, Water Research 36, 4064-4078, 2002.

[14] A. Bukhari, Investigation of the electro-coagulation treatment process for the removal of total suspended solids and turbidity from municipal wastewater, Bioresource Technology 99, 914-921, 2008.

[15] M. Bayramoglu, M. Eyvaz, M. Kobya, Treatment of the textile wastewater by electrocoagulation Economical evaluation, Chemical Engineering Journal 128, 155-161, 2007.

[16] Wagh Manoj, Nemade P. D., Dhasal S. R., Colour and COD removal of Distillery spent wash by using Electro coagulation, International Journal of Engineering Research and General Science 3(3), 1159-1171, 2015.

[17] Wagh M. P., Nemade P. D. Treatment Processes and Technologies for Decolourization and COD Removal of Distillery Spent Wash: A Review, International Journal of Innovative Research in Advanced Engineering, 7(2), 30-40, 2015.

[18] Nemade P. D. Arsenite and Arsenate removal from water by Household bucket filter, International journal of water research, 5(2), 58-63, 2015.

[19] D. Ghosh, H. Solanki, M.K. Purkait, Removal of Fe (II) from tap water by electrocoagulation technique, Journal of Hazardous Materials, 155 135-143, 2008.
[20] D. Ghernaout, et al., Application of electrocoagulation in Escherichia coli culture and two surface waters, Desalination, 219, 118-125, 2018.

[21] M. Kobya, et al., Treatment of potato chips manufacturing wastewater by electrocoagulation, Desalination 190, 201-211, 2006.

[22] N. Mameri, et al., De fluoridation of septentrional Sahara water of north Africa by electro coagulation process using bipolar aluminium electrodes, Water Research, 32, 1604-1612, 1998.

[23] Nehal M. Ashour, Mohamed Bassyouni, Mamdouh Y. Saleh, Removal of heavy metals from industrial wastewater using fly ash on pilot scale, International Journal of Emerging Trends in Engineering Research, Volume 8. No. 9, 5242-5247, September 2020. 